\title{
Vitamin and mineral levels in children with autism spectrum disorder
}

\author{
Mehmet Palaz ${ }^{1}$, Hasret Ayyildiz Civan ${ }^{2}$, Semra Yılmaz ${ }^{3}$, Didem Gülcü Taşkın ${ }^{4}$ \\ ${ }^{1}$ Department of Child Health and Diseases, University of Health Sciences, Johor, Malaysia \\ ${ }^{2}$ Department of Child and Adolescent Psychiatry and Mental HealthUniversity of Health \\ Sciences, Johor, Malaysia \\ ${ }^{*}$ Corresponding author, Ðe-mail: hasretayyildiz@yahoo.com
}

\begin{abstract}
The aim of this study was to compare the vitamin and mineral values of the patients followed up in the Child Psychiatry Outpatient Clinic with the diagnosis of autism spectrum disorder to healthy controls in the same age group and to investigate whether vitaminmineral values were related to autism weight (CARS score). Between September 2017 and September 2018, we worked at Bakırköy Dr. Sadi Konuk Training and Research Hospital Children and Adolescent Mental Health and Diseases outpatient clinic with autism spectrum disorder patients with childhood autism assessment scale (CARS) was weighted. Age, gender, height, weight, blood Iron, Vitamin B12, Folate and $25(\mathrm{OH})$ Vitamin D levels of all patients included in the study were recorded. Mann-Whitney U, Pearson chi-square and Fisher's exact test were used to evaluate the data. In this study, 108 patients with ASD were compared with 115 normal cases. There was no statistically significant decrease in Vitamin B12, Folate, Iron and Vitamin D levels in patients with ASD compared to normal patients. According to CARS score, there was no statistically significant difference in vitamin B12, Folate, Iron and Vitamin D levels in children with mild and severe ASD. In our study, it was concluded that vitamin B12, Folate, Iron and Vitamin D levels in children with ASD were not lower than healthy children, and there was no difference between mild and severe cases according to CARS score.
\end{abstract}

Keywords: Autism, vitamin, mineral, CARS.

How to Cite: Palaz, M., Civan, H., \& Y1lmaz, S. (2020). Vitamin and mineral levels in children with autism spectrum disorder. COUNS-EDU: The International Journal of Counseling and Education, 5(3), 87100. DOI: http://dx.doi.org/10.23916/0020200528030

This is an open access article distributed under the Creative Commons Attribution License, which permits unrestricted use, distribution, and reproduction in any medium, provided the original work is properly cited. (C2020 by author.

\section{Introduction}

Autism spectrum disorder (ASD) is a neurodevelopmental disorder that appears in the first years of development and causes social interaction and communication problems as well as severely limited interest and repetitive behaviors (Association, 1995). ASD is a lifelong disorder that is observed in 1 out of 68 to 150 children in current studies. Since there is no cure for the main symptoms of the disease, it is considered as a significant problem in society(Baio et al., 2018; Bauman, 2010; Buie et al., 2010; Gorrindo et al., 2012; Ibrahim, Voigt, Katusic, Weaver, \& Barbaresi, 2009; Mouridsen, Rich, \& Isager, 2010).

Patients mostly present with delayed speech at 2-3 years of age. While some patients experience restrictions from birth, some patients may go through regression after normal development. This age group shows signs such as preference of being alone, indifference to adults, playing alone and failing to respond to their name (Çetin Çuhadaroğlu et al., 2008). 
Restricted gestures and mimics, having trouble communicating with others, indifference to peers and failure to keep relations with peers are common in the preschool period. Shorter sentences, repetitive talking, repeating words or phrases and a monotone voice is observed (Çetin Çuhadaroğlu, et al., 2008).

Sudden and delayed echolalia, contradiction in pronouns, problems with the tone of voice, neologism and repetitive talking are common in the school period. While there is no deterioration in adolescence and adulthood, certain behavioral problems, resistance to change, tantrums, causing self-harm and harming others are frequently observed (Çetin Çuhadaroğlu, et al., 2008).

Severity is determined by criteria such as intensity of autistic signs, effects on human relations and daily living and any accompanying mental retardation. The severity of ASD is classified by the Childhood Autism Rating Scale (CARS) as mild, moderate and severe. Determination of the disease severity in early childhood is highly beneficial for determination of possible interventions, required medical treatments and future expectations (Eaves \& Ho, 2008).

The Childhood Autism Rating Scale (CARS) is a behavioral rating scale designed to differentiate children with autistic symptoms and non-autistic children with mental retardation, consisting of 15 items where each item is rated with a half score of 1-4.

The most common comorbidities in children with ASD are mental retardation, sensory disorders, gastrointestinal dysfunction, sleep disturbance and autoimmune disorders (Association, 1995). Atypical nutritional behaviors and nutrition problems are common in children diagnosed with Autism Spectrum Disorder (ASD). Poor nutritional behaviors include refusing foods, limited food preferences, refusing family diet, obsessive meal time routines, inappropriate feeding patterns and emotional dietary preferences. Children with ASD are reported to have a five times higher probability of eating disorders compared to healthy peers (Bauman, 2010; Buie, et al., 2010; Gorrindo, et al., 2012; Ibrahim, et al., 2009; Mouridsen, et al., 2010).

Parents of ASD patients report that their children are selective in their diets and have limited food intake (Kodak \& Piazza, 2008). Patients with ASD may experience nutritional problems, selectivity, different feeding habits as well as insistence on certain food patterns, refusing to try new food, eating only a certain type of food too much or too little and mealtime behavioral problems (Bandini et al., 2017). Reduced diversity of food and eating limited types of food too much result in vitamin and mineral insufficiency and pose a risk for health and development of children (Herndon, DiGuiseppi, Johnson, Leiferman, \& Reynolds, 2009).

Although the reports of nutrition for children with ASD have provided contradictory results, many studies have shown that individuals with ASD have selective feeding habits and a daily intake usually below the recommended levels and thus may be at risk of vitamin and mineral insufficiency (Graf-Myles et al., 2013).

Vitamins and minerals are necessary for the normal structure and basic function of central nervous system, promoting cell differentiation, development and migration. Insufficient intake of some micronutrients may have a negative impact on brain structure or function (Curtis \& Patel, 2008). Many studies have indicated the relationship between vitamins and neurodevelopmental as well as cognitive function and the majority of the results have been associated with the impact of foods on the central nervous system (N. Khan et al., 2015; N. A. Khan, Raine, Drollette, Scudder, \& Hillman, 2015).

The objective of this study was to compare the vitamin and mineral levels of patients diagnosed with autism spectrum disorder and followed by the Child Psychiatry polyclinic versus healthy controls in the same age group and investigate any relationship between vitamin-mineral levels and severity of autism (CARS score). The results of this study and similar studies can be considered to increase awareness of physicians about vitamin and mineral insufficiency in ASD patients and provide guidance for nutritional management.

\section{Method}

There is 108 children presenting to Bakirkoy Dr. Sadi Konuk Training and Research Hospital, Child and Adolescent Psychiatry Polyclinic and diagnosed with Autism Spectrum Disorder (ASD) were included in this study as the patient group following the ethics committee approval. The patient group was 
divided into 2 subgroups: patients with a CARS score of 30-36 (=mild to moderate autistic) and 37-60 (=severely autistic).

The control group consisted of 115 healthy children presenting to Bakirkoy Dr. Sadi Konuk Training and Research Hospital, Child and Adolescent Psychiatry Polyclinic with matching age and gender. Written consent was obtained from all families who accepted to participate in the study. The study was approved by the Bakirkoy Dr. Sadi Konuk Training and Research Hospital Clinical Trials Ethics Committee.

Patients' height was measured using a Holtain Harpenden 603 VR portable stadiometer and their body weight was measured with a SECA 769 scale. Birth dates and first presentation dates were obtained from the patient record system and their height and weight SDS values were calculated using the auxology formulations from the website ceddcozum.com by the Association of Pediatric Endocrinology and Diabetes.

Taking literature studies as a model, the cut-off values were determined as $<200 \mathrm{pg} / \mathrm{dl}$ for Vitamin $\mathrm{B} 12,<50 \mu \mathrm{g} / \mathrm{dL}$ for iron, $<30 \mathrm{ng} / \mathrm{ml}$ for Vitamin $\mathrm{D}$ and $<5 \mathrm{ng} / \mathrm{ml}$ for Folate. A $2 \mathrm{ml}$ venous blood sample was collected from each patient into yellow and purple EDTA tubes. The levels of vitamin B12 and folate were analyzed using electrochemiluminescence, iron levels using photometric methods, serum $25(\mathrm{OH})$ vitamin D using immunoassay methods with a Cobas 6000 (Roche Diagnostics, USA) and hemogram was analyzed using a flow cytometry method with a Sysmex device.

Patient data was recorded into a standard data sheet and coded to be computerized. This sheet included gender, decimal age, height, height SDS, weight, weight SDS, $25(\mathrm{OH})$ Vitamin D, Vitamin B12, Folate and Iron results. Demographics, anthropometric measurements and laboratory parameters of the patient and control groups were statistically compared.

\section{Results and Discussions}

It is a Likert scale based on observation of behaviors, consisting of 15 items where each item is scored 1 to 4 . Children's relationship with other people, body and object usage, adaptation to changes, verbal and non-verbal communication and imitation abilities as well as sensorial characteristics, fears and activity levels are scored by professionals. A score of 1 defines normal behavior while 4 defines abnormal inappropriate behavior.

The patients with a CARS score of 37-60 are included into the autistic group with severe symptoms, 30-36.5 are included into the autistic group with mild to moderate symptoms whereas a score of 15 to 29.5 are included into the group without autistic symptoms.

The scale was developed by Schopler et al. in 1980 as an aid in the diagnosis of autism. CARS has been shown to be highly correlated with DSM-III and DSM-III-R and is considered to be largely correlated with DSM-IV. Although there is no Turkish validity and reliability studies, CARS has been used in previous studies of autism in Turkey (Özkan \& BK, 2007).

\section{Statistical analysis}

Statistical analysis was performed by NCSS (Number Cruncher Statistical System) 2007 (Kaysville, Utah, USA). Descriptive statistical methods (mean, standard deviation, median, frequency, percentage, minimum and maximum) were used for study data evaluation. Quantitative data was tested for normal distribution using the Shapiro-Wilk test and graphical evaluation. Independent samples t-test was used for intergroup comparison of quantitative variables with normal distribution and Mann-Whitney U test was used for intergroup comparison of quantitative variables without normal distribution. The Pearson chisquare test and Fisher's exact test were used for qualitative data comparison. $p<0.05$ was considered as statistically significant.

\section{Results}

This study was performed between September 2017 - September 2018 in Bakirkoy Dr. Sadi Konuk Training and Research Hospital on 223 pediatric cases, with $48.4 \%(n=108)$ in the autistic group and $51.6 \%(n=115)$ in the control group. $69.1 \%(n=154)$ of the cases were male and $30.9 \%(n=69)$ were female; their ages varying between 0.6 and 15 with a mean of $7.03 \pm 3.44$ years. 
Weight $Z$ scores varied between -2.5 and 3.7 with a mean of $0.32 \pm 1.30$ and height $Z$ scores varied between -3 and 3.4 with a mean of $0.36 \pm 1.28$. Hemoglobin levels varied between 9.6 and 16.9 with a mean of $12.48 \pm 1.01$ and iron levels varied between 6 and 284 with a mean of $69.79 \pm 37.96$. Vitamin B12 levels

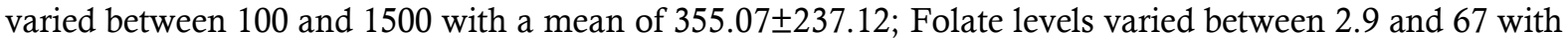
a mean of $11.41 \pm 5.93$ and Vitamin D levels varied between 4.8 and 218 with a mean of $23.32 \pm 19.82$. CARS scores of the autistic group varied between 30.5 and 51 with a mean of $34.87 \pm 4.13$. According to the CARS score, $66.7 \%(n=72)$ of the autistic cases were mild and $33.3 \%(n=36)$ were severe. No statistically significant difference was determined between mean ages by groups $(p>0.05)$.

A statistically significant difference was determined between gender distribution by groups $(p=0.001 ; p<0.01)$; the autistic group has a higher rate of males compared to the control group. The weight $\mathrm{Z}$ score of the autistic group was determined to be statistically significantly higher than the control group $(p=0.002 ; p<0.01)$. The height $Z$ score of the autistic group was determined to be statistically significantly higher than the control group $(p=0.001 ; p<0.01)$. No statistically significant difference was determined between Hemoglobin and Iron measurements by groups ( $p>0.05)$. No statistically significant difference was determined between vitamin B12 measurements of the autistic group and control group measurements $(p=0.051 ; p<0.05)$. No statistically significant difference was determined between Folate measurements by groups $(\mathrm{p}>0.05)$.

The vitamin $\mathrm{D}$ measurements of the autistic group was determined to be statistically significantly higher than the control group $(\mathrm{p}=0.001 ; \mathrm{p}<0.01)$. No statistically significant difference was determined between iron, vitamin B12 and folate measurements by groups $(p>0.05)$. A statistically significant difference was determined between vitamin $\mathrm{D}$ levels by groups $(\mathrm{p}=0.001 ; \mathrm{p}<0.01)$; the autistic group had a higher rate of normal vitamin D levels compared to the control group. No statistically significant difference was determined between mean ages of cases with a mild and severe CARS level $(p>0.05)$.

The CARS level by gender demonstrates no statistically significant difference $(p>0.05)$. No statistically significant difference was determined between weight and height $\mathrm{Z}$ scores of cases with a mild and severe CARS level $(p>0.05)$. No statistically significant difference was determined between Hemoglobin and Iron measurements of cases with a mild and severe CARS level $(\mathrm{p}>0.05)$. No statistically significant difference was determined between vitamin B12, Folate and vitamin D measurements by CARS level ( $p>0.05)$. No statistically significant difference was determined between iron, vitamin B12, folate and vitamin D levels by CARS level ( $p>0.05$ ). No statistically significant correlation was determined between CARS scores and Hemoglobin and Iron measurements $(p>0.05)$. No statistically significant correlation was determined between CARS scores and vitamin B12, Folate and vitamin D measurements $(\mathrm{p}>0.05)$.

\section{Discussion}

The autistic patient group of 108 patients included in the study consisted of $94(87 \%)$ male and $14(13 \%)$ female patients with a male/female ratio of 6.7/1. A study by Gormez et al. showed that patients with autism consisted of $11.1 \%$ female and $88.9 \%$ male patients while a study by Ugur et al. showed that 130 children diagnosed with ASD consisted of $80 \%$ male patients. These studies indicate that the demographics distribution in our study is consistent with the literature. However, the CARS level by gender did not demonstrate a statistically significant difference; disease severity was similar in both gender $(\mathrm{p}>0.05)$.

In our study, the weight $Z$ score $(0.59 \pm 1.27)$ and height $Z$ score $(0.65 \pm 1.27)$ of the autistic group was determined to be statistically significantly higher compared to the weight $Z$ score $(0.06 \pm 1.29)$ and height $Z$ score $(0.09 \pm 1.23)$ of the control group. The autistic group included $13(12 \%)$ patients with a weight $Z$ score $>2$ and $11(10 \%)$ patients with a height $Z$ score $>2$ whereas the control group included 12 $(10 \%)$ patients with a weight $Z$ score $>2$ and $7(6 \%)$ patients with a height $Z$ score $>2$. When the CARS levels were analyzed, no statistically significant difference was determined between mean weight and height of mild and severe cases. In studies by Sun, De Vinck-Baroody, Dreyer Gillette and Meguid et al., weight and height $\mathrm{Z}$ scores of ASD patients were higher than the control groups, which was similar to the results of our study. However, the studies by Xiao Liu and Marí-Bauset et al. showed lower weight and height $\mathrm{Z}$ scores in the ASD group compared to the control group (18). This difference may result from the selective diets of children with ASD, reduced diversity of food, nutritional deficiency and susceptibility to obesity due to high-carbohydrate feeding. 
The ASD group had a mean iron level of $70.96 \pm 35.17$ compared to $68.70 \pm 40.51$ in the control group with no statistically significant difference $(\mathrm{p}=0.449)$. There were 28 patients $(25.9 \%)$ with low iron levels in the ASD group compared to 38 patients (33\%) in the control group. According to an evaluation of CARS scores, low iron levels were found in $18(25 \%)$ patients with mild autism and $10(27.8 \%)$ patients with severe autism, without any statistically significant correlation to disease severity. In a study, iron deficiency (ID) was detected in $50 \%$ of children up to 5 years of age, $45 \%$ of children between $5-15$ years and iron deficiency anemia (IDA) was detected in 50\% of children with ID. The studies performed in Turkey revealed an IDA of 15-60\% (Kilinç, Yüregir, \& Ekerbiçer, 2002). The studies by Gunes , Liu, Bener et al. showed lower iron levels in the ASD patient groups than the control groups when compared to our study (Bener, Khattab, Bhugra, \& Hoffmann, 2017; Gunes, Ekinci, \& Celik, 2017). Iron plays an important role in early brain development and brain functions. Many studies have shown that iron deficiency has an impact on psychomotor development. Iron deficiency is a systemic condition that affects more than 200 enzyme functions, cellular oxygen carrying capacity and use, energy use, hormone regulation, muscle functioning and physical performance, defense mechanisms against infection, intestinal absorption as well as growth and development. It is one of the curable causes of psychomotor retardation if treated early. Lozoff et al. reported that early iron deficiency led to a permanent damage on nervous system development and function, resulting in cognitive disorder, reduced learning capacity and attention span, and neuromotor dysfunction. It was demonstrated that iron supplements improved behavior, growth and psychomotor development in young children with iron deficiency (Lozoff, Jimenez, \& Wolf, 1991). In a study by Otero et al. of 33 primary school students, it was observed that children with ID had a lower average IQ scores compared to those with normal iron levels (Otero, Aguirre, Porcayo, \& Fernandez, 1999). These findings indicate that iron is essential for normal development and function of nervous system. Therefore, it is recommended to include iron parameters into routine analyses of children diagnosed with ASD having a selective or low iron diet (such as excessive amounts of cow's milk).

$7(6.5 \%)$ patients in the ASD group and $5(4.3 \%)$ patients in the control group had a low folate level with no statistically significant difference. Considering Vitamin B12 levels, 19 (17.6\%) patients in the ASD group and $26(22.6 \%)$ patients in the control group had low levels with no statistically significant difference. Considering CARS scores, there were $3(4.2 \%)$ mildly autistic patients and $4(11.1 \%)$ severely autistic patients with low folate levels versus $13(18.1 \%)$ mildly autistic patient and $6(16.7 \%)$ severely autistic patients with low vitamin B12 levels; there was no statistically significant correlation to disease severity. The studies by Bala, Altun, Meguid, Ali A et al. demonstrated low B12 and folate levels while Ugur C, Esnafoglu and Liu et al. determined no significant difference in vitamin B12 and folate levels, which was similar to the results of our study (Ali et al., 2011; Altun, Kurutaş, Şahin, Güngör, \& Fındıkl1, 2018; Bala et al., 2016; ESNAFOĞLU; Meguid, Hashish, Anwar, \& Sidhom, 2010; Uğur \& Gürkan, 2014). The studies by Altun, Gong, Mostafa and Esnafoglu detected a negative correlation between the CARS scores and B12 levels and reported that the increase in homocysteine observed in Vitamin B12 and folate deficiency was associated with the ASD pathophysiology and could be used as a diagnostic tool for determination of vitamin insufficiency in children with autism (Kałużna-Czaplińska, Żurawicz, Michalska, \& Rynkowski, 2013). It was demonstrated that hyperhomocysteinemia, which may result from deficiency of vitamins related with single-carbon metabolism such as vitamin B12 and folate deficiency, had a significant and direct association with lack of communication in children with ASD (Puig-Alcaraz, Fuentes-Albero, Calderón, Garrote, \& Cauli, 2015). Based on the evaluation of all results, the singlecarbon metabolism involving vitamin $\mathrm{B} 12$, folate and homocysteine can be considered to contribute to the ASD etiology or increase the severity of autism.

Vitamin D plays an important role in brain development and functions such as brain proliferation, differentiation, neurotransmission, myelination, neuron protection and neuroplasticity. In addition, it has functions of DNA stabilization, autoimmune suppression, anti-inflammatory activities, mitochondrial protection and protection against oxidative stress.80 (74.1\%) patients in the ASD group and $103(89.6 \%)$ patients in the control group had low levels of vitamin $\mathrm{D}$, which was considered as statistically significant. According to CARS scores, $54(75.0 \%)$ cases with mild autism and $26(72.2 \%)$ cases with severe autism had low levels of vitamin D with no statistically significant difference. Bala, Altun, Mostafa, Bener et al. found significantly low vitamin D levels in the ASD group while El-Ansary, Gong, Mostafa and Esnafoglu determined a significant negative correlation with the CARS scores (El-Ansary et al., 2018; Gong et al., 2014; Mostafa \& Al-Ayadhi, 2012). However, Ugur, Xiao Liu and Hashemzadeh determined no significant difference between the autistic and normal groups; Liu and Hashemzadeh demonstrated that 
there was no statistically significant correlation to the CARS scores (Hashemzadeh, Moharreri, \& SOltanifar, 2015). This variation in our study was considered to result from a seasonal variation since blood samples of patient and control groups for serum $25(\mathrm{OH})$ Vitamin D levels were not drawn within the same period. Thus, the possibility of vitamin D levels contributing to the ASD etiology cannot be excluded. On the other hand, it may be inappropriate to relate clinical features of ASD with vitamin D alone as ASD has a multifactorial etiology combining genetic, environmental and possible immunological factors.

\section{Conclusions}

Height and weight SDS of the ASD patient group was determined to be statistically significantly higher than the control group. There was no significant difference between the height and weight SDS of the patients with mild and severe ASD according to the SARS score. The vitamin D levels of the ASD patient group were statistically significantly higher than the vitamin D levels of the control group. However, it was considered that this difference could be related to a seasonal variation. There was no significant difference between the vitamin D levels of the patients with mild and severe ASD according to the SARS score. No statistically significant difference was determined between the Vitamin B12, Folate and Iron levels of the ASD patient group and the control group. There was no significant difference between the Vitamin B12, Folate and Iron levels of the patients with mild and severe ASD according to the SARS score. In our study, vitamin D, Vitamin B12, Folate and Iron levels of children with ASD was not lower than healthy children. Based on these findings, it is considered that analysis of these vitamin and mineral levels in ASD patients in clinical practice alone may not contribute to treatment.

\section{References}

Ali, A., Waly, M. I., Al-Farsi, Y. M., Essa, M. M., Al-Sharbati, M. M., \& Deth, R. C. (2011). Hyperhomocysteinemia among Omani autistic children: a case-control study. Acta Biochimica Polonica, 58(4).

Altun, H., Kurutaş, E. B., Şahin, N., Güngör, O., \& Fındıklı, E. (2018). The levels of vitamin D, vitamin $\mathrm{D}$ receptor, homocysteine and complex B vitamin in children with autism spectrum disorders. Clinical Psychopharmacology and Neuroscience, 16(4), 383.

Association, A. P. (1995). Association, AP Diagnostic and statistical manual of mental disorders. Arlington, VA, US: American Psychiatric Publishing, Inc.

Baio, J., Wiggins, L., Christensen, D. L., Maenner, M. J., Daniels, J., Warren, Z., . . White, T. (2018). Prevalence of autism spectrum disorder among children aged 8 years-autism and developmental disabilities monitoring network, 11 sites, United States, 2014. MMWR Surveillance Summaries, 67(6), 1.

Bala, K., Dogan, M., Mutluer, T., Kaba, S., Aslan, O., Balahoroglu, R., . . Kocaman, S. (2016). Plasma amino acid profile in autism spectrum disorder (ASD). Eur Rev Med Pharmacol Sci, 20(5), 923-929.

Bandini, L. G., Curtin, C., Phillips, S., Anderson, S. E., Maslin, M., \& Must, A. (2017). Changes in food selectivity in children with autism spectrum disorder. Journal of autism and developmental disorders, 47(2), 439-446.

Bauman, M. L. (2010). Medical comorbidities in autism: challenges to diagnosis and treatment. Neurotherapeutics, 7(3), 320-327.

Bener, A., Khattab, A. O., Bhugra, D., \& Hoffmann, G. F. (2017). Iron and vitamin D levels among autism spectrum disorders children. Annals of African medicine, 16(4), 186.

Buie, T., Campbell, D. B., Fuchs, G. J., Furuta, G. T., Levy, J., VandeWater, J., . . B Beaudet, A. L. (2010). Evaluation, diagnosis, and treatment of gastrointestinal disorders in individuals with ASDs: a consensus report. Pediatrics, 125(Supplement 1), S1-S18.

Çetin Çuhadaroğlu, F., Pehlivantürk, B., Ünal, F., Uslu, R., İşeri, E., Türkbay, T., . . Motavalli, N. (2008). Çocuk ve Ergen Psikiyatrisi Temel Kitabı. 1. Basım. Ankara. Hekimler Yayın Birliği.

Curtis, L. T., \& Patel, K. (2008). Nutritional and environmental approaches to preventing and treating autism and attention deficit hyperactivity disorder (ADHD): a review. The Journal of Alternative and Complementary Medicine, 14(1), 79-85.

Eaves, L. C., \& Ho, H. H. (2008). Young adult outcome of autism spectrum disorders. Journal of autism and developmental disorders, 38(4), 739-747. 
El-Ansary, A., Bjørklund, G., Khemakhem, A. M., Al-Ayadhi, L., Chirumbolo, S., \& Bacha, A. B. (2018). Metabolism-associated markers and Childhood Autism Rating Scales (CARS) as a measure of autism severity. Journal of Molecular Neuroscience, 65(3), 265-276.

ESNAFOĞLU, E. Otistik Spektrum Bozukluğu BulunanÇocuklarda Vitamin B12, Folat ve Vitamin D Seviyelerinin İncelenmesi. Klinik Tıp Aile Hekimliği, 9(4), 36-41.

Gong, Z.-L., Luo, C.-M., Wang, L., Shen, L., Wei, F., Tong, R.-J., \& Liu, Y. (2014). Serum 25hydroxyvitamin D levels in Chinese children with autism spectrum disorders. Neuroreport, 25(1), 2327.

Gorrindo, P., Williams, K. C., Lee, E. B., Walker, L. S., McGrew, S. G., \& Levitt, P. (2012). Gastrointestinal dysfunction in autism: parental report, clinical evaluation, and associated factors. Autism Research, 5(2), 101-108.

Graf-Myles, J., Farmer, C., Thurm, A., Royster, C., Kahn, P., Soskey, L., . . . Swedo, S. (2013). Dietary adequacy of children with autism compared to controls and the impact of restricted diet. Journal of developmental and behavioral pediatrics: JDBP, 34(7).

Gunes, S., Ekinci, O., \& Celik, T. (2017). Iron deficiency parameters in autism spectrum disorder: clinical correlates and associated factors. Italian journal of pediatrics, 43(1), 1-6.

Hashemzadeh, M., Moharreri, F., \& SOltanifar, A. (2015). Comparative study of vitamin D levels in children with autism spectrum disorder and normal children: A case-control study. Journal of Fundamentals of Mental Health, 17(4), 197-201.

Herndon, A. C., DiGuiseppi, C., Johnson, S. L., Leiferman, J., \& Reynolds, A. (2009). Does nutritional intake differ between children with autism spectrum disorders and children with typical development? Journal of autism and developmental disorders, 39(2), 212-222.

Ibrahim, S. H., Voigt, R. G., Katusic, S. K., Weaver, A. L., \& Barbaresi, W. J. (2009). Incidence of gastrointestinal symptoms in children with autism: a population-based study. Pediatrics, 124(2), 680686.

Kałużna-Czaplińska, J., Żurawicz, E., Michalska, M., \& Rynkowski, J. (2013). A focus on homocysteine in autism. Acta Biochimica Polonica, 60(2).

Khan, N., Raine, L., Drollette, E., Scudder, M., Cohen, N., Kramer, A., \& Hillman, C. (2015). The relationship between total water intake and cognitive control among prepubertal children. Annals of Nutrition and Metabolism, 66(Suppl. 3), 38-41.

Khan, N. A., Raine, L. B., Drollette, E. S., Scudder, M. R., \& Hillman, C. H. (2015). The relation of saturated fats and dietary cholesterol to childhood cognitive flexibility. Appetite, 93, 51-56.

Kilinç, M., Yüregir, G. T., \& Ekerbiçer, H. (2002). Anaemia and iron-deficiency anaemia in south-east Anatolia. European journal of haematology, 69(5-6), 280-283.

Kodak, T., \& Piazza, C. C. (2008). Assessment and behavioral treatment of feeding and sleeping disorders in children with autism spectrum disorders. Child and adolescent psychiatric clinics of North America, $17(4), 887-905$.

Lozoff, B., Jimenez, E., \& Wolf, A. W. (1991). Long-term developmental outcome of infants with iron deficiency. New England journal of medicine, 325(10), 687-694.

Meguid, N. A., Hashish, A. F., Anwar, M., \& Sidhom, G. (2010). Reduced serum levels of 25-hydroxy and 1, 25-dihydroxy vitamin D in Egyptian children with autism. The Journal of Alternative and Complementary Medicine, 16(6), 641-645.

Mostafa, G. A., \& Al-Ayadhi, L. Y. (2012). Reduced serum concentrations of 25-hydroxy vitamin D in children with autism: relation to autoimmunity. Journal of neuroinflammation, 9(1), 1-7.

Mouridsen, S., Rich, B., \& Isager, T. (2010). A longitudinal study of gastrointestinal diseases in individuals diagnosed with infantile autism as children. Child: care, health and development, 36(3), $437-$ 443.

Otero, G. A., Aguirre, D. M., Porcayo, R., \& Fernandez, T. (1999). Psychological and electroencephalographic study in school children with iron deficiency. International journal of neuroscience, 99(1-4), 113-121.

Özkan, B., \& BK, Y. (2007). Rikets. Güncel Çocuk Sağlı̆̆ı, 5(1), 34-41.

Puig-Alcaraz, C., Fuentes-Albero, M., Calderón, J., Garrote, D., \& Cauli, O. (2015). Increased homocysteine levels correlate with the communication deficit in children with autism spectrum disorder. Psychiatry research, 229(3), 1031-1037. 
Uğur, Ç., \& Gürkan, C. K. (2014). Serum vitamin D and folate levels in children with autism spectrum disorders. Research in Autism Spectrum Disorders, 8(12), 1641-1647. 
Table 1. Distribution of Descriptive Characteristics

\begin{tabular}{cll}
\hline Descriptive Characteristics & & \\
\hline Age (years) & Min-Max (Median) & $0.6-15(7)$ \\
\cline { 2 - 3 } & Mean $\pm S d$ & $7.03 \pm 3.44$ \\
\hline Gender; $\boldsymbol{n}(\%)$ & Male & $154(69.1)$ \\
\cline { 2 - 3 } & Female & $69(30.9)$ \\
\hline Weight Z $\mathbf{Z}$ score & Min-Max (Median) & $-2.5-3.7(0.2)$ \\
\cline { 2 - 3 } & Mean $\pm S d$ & $0.32 \pm 1.30$ \\
\hline Height Z $\mathbf{Z}$ score & Min-Max (Median) & $-3-3.4(0.5)$ \\
\cline { 2 - 3 } & Mean $\pm S d$ & $0.36 \pm 1.28$ \\
\hline
\end{tabular}

Table 2. Distribution of Vitamin and Mineral Measurements

\begin{tabular}{|c|c|c|}
\hline \multicolumn{3}{|c|}{ Vitamin and Mineral Measurements } \\
\hline \multirow[t]{2}{*}{ Hemoglobin } & Min-Max (Median) & $9.6-16.9(12.5)$ \\
\hline & Mean $\pm S d$ & $12.48 \pm 1.01$ \\
\hline \multirow[t]{4}{*}{ Iron } & Min-Max (Median) & $6-284(62.1)$ \\
\hline & Mean $\pm S d$ & $69.79 \pm 37.96$ \\
\hline & Low; $n(\%)$ & $66(29.6)$ \\
\hline & Normal; $n(\%)$ & $157(70.4)$ \\
\hline \multirow[t]{4}{*}{ Vitamin B12 } & Min-Max (Median) & $100-1500(306)$ \\
\hline & Mean $\pm S d$ & $355.07 \pm 237.12$ \\
\hline & Low; $n(\%)$ & $45(20.2)$ \\
\hline & Normal; $n(\%)$ & $178(79.8)$ \\
\hline \multirow[t]{4}{*}{ Folate } & Min-Max (Median) & $2.9-67(10.6)$ \\
\hline & Mean $\pm S d$ & $11.41 \pm 5.93$ \\
\hline & Low; n(\%) & $12(5.4)$ \\
\hline & Normal; $n(\%)$ & $211(94.6)$ \\
\hline \multirow[t]{4}{*}{ Vitamin D } & Min-Max (Median) & $4.8-218(20)$ \\
\hline & Mean $\pm S d$ & $23.32 \pm 19.82$ \\
\hline & Low; $n(\%)$ & $183(82.1)$ \\
\hline & Normal; $n(\%)$ & $40(17.9)$ \\
\hline
\end{tabular}

Table 3. Distribution of CARS Scores of the Autistic Group

CARS score $(n=108)$

\begin{tabular}{ll} 
Min-Max (Median) & $\mathbf{3 0 . 5 - 5 1}(\mathbf{3 3})$ \\
\hline Mean \pm Sd & $34.87 \pm 4.13$ \\
\hline Mild & $72(66.7)$ \\
\hline Severe & $36(33.3)$
\end{tabular}

Table 4. Evaluation of Descriptive Characteristics by Group

\begin{tabular}{lllll}
\hline & & $\begin{array}{l}\text { Autistic group } \\
(\mathrm{n}=108)\end{array}$ & $\begin{array}{l}\text { Control group } \\
(\mathrm{n}=115)\end{array}$ & $P$ \\
Age (years) & Min-Max (Median) & $2-15(7)$ & $0.6-15(7)$ & ${ }^{a} 0.543$ \\
& Mean $\pm S d$ & $6.89 \pm 2.76$ & $7.17 \pm 3.99$ & \\
Gender; $n$ (\%) & Male & $94(87.0)$ & $60(52.2)$ & ${ }^{b} 0.001^{* *}$ \\
& Female & $14(13.0)$ & $55(47.8)$ & \\
Weight Z score & Min-Max (Median) & $-2.4-3.5(0.5)$ & $-2.5-3.7(-0.2)$ & ${ }^{a} 0.002^{* *}$ \\
& Mean \pm Sd & $0.59 \pm 1.27$ & $0.06 \pm 1.29$ & \\
Height Z score & Min-Max (Median) & $-3-3.2(0.9)$ & $-2.8-3.4(-0.2)$ & ${ }^{a} 0.001^{* *}$ \\
& Mean \pm Sd & $0.65 \pm 1.27$ & $0.09 \pm 1.23$ & \\
& ${ }^{b}$ Pearson Chi-Square Test & ${ }^{* *} p<0.01$ &
\end{tabular}


Table 5. Evaluation of Vitamin and Mineral Measurements by Groups

\begin{tabular}{|c|c|c|c|c|}
\hline & & $\begin{array}{l}\text { Autistic group } \\
(n=108)\end{array}$ & $\begin{array}{l}\text { Control group } \\
(n=115)\end{array}$ & $P$ \\
\hline \multirow[t]{2}{*}{ Hemoglobin } & Min-Max (Median) & $9.6-14.6(12.5)$ & $10.5-16.9(12.4)$ & ${ }^{a} 0.323$ \\
\hline & Mean $\pm S d$ & $12.41 \pm 0.88$ & $12.54 \pm 1.13$ & \\
\hline \multirow[t]{2}{*}{ Iron } & Min-Max (Median) & $10-175(63)$ & $6-284(62)$ & ${ }^{c} 0.449$ \\
\hline & Mean $\pm S d$ & $70.96 \pm 35.17$ & $68.70 \pm 40.51$ & \\
\hline \multirow[t]{2}{*}{ Iron levels } & Low $(<50)$ & $28(25.9)$ & $38(33.0)$ & ${ }^{b} 0.245$ \\
\hline & Normal $(\geq 50)$ & $80(74.1)$ & $77(67.0)$ & \\
\hline \multirow[t]{2}{*}{ Vitamin B12 } & Min-Max (Median) & $107-1500(329)$ & $100-675(285)$ & ${ }^{c} 0.051$ \\
\hline & Mean $\pm S d$ & $402.45 \pm 305.09$ & $312.05 \pm 134.96$ & \\
\hline \multirow[t]{2}{*}{ Vitamin B12 levels } & Low $(<200)$ & $19(17.6)$ & $26(22.6)$ & ${ }^{b} 0.351$ \\
\hline & Normal $(\geq 200)$ & $89(82.4)$ & $89(77.4)$ & \\
\hline \multirow[t]{2}{*}{ Folate } & Min-Max (Median) & $3.4-24(10.6)$ & $2.9-67(10.4)$ & ${ }^{c} 0.755$ \\
\hline & Mean $\pm S d$ & $11.08 \pm 4.63$ & $11.72 \pm 6.94$ & \\
\hline \multirow[t]{2}{*}{ Folate levels } & Low $(<5)$ & $7(6.5)$ & $5(4.3)$ & ${ }^{b} 0.480$ \\
\hline & Normal $(\geq 5)$ & $101(93.5)$ & $110(95.7)$ & \\
\hline \multirow[t]{2}{*}{ Vitamin D } & Min-Max (Median) & $6.5-218(23)$ & $4.8-141.5(16.8)$ & ${ }^{c} 0.001^{* *}$ \\
\hline & Mean $\pm S d$ & $27.68 \pm 23.80$ & $19.27 \pm 14.15$ & \\
\hline \multirow[t]{2}{*}{ Vitamin D levels } & Low $(<30)$ & $80(74.1)$ & $103(89.6)$ & ${ }^{b} 0.003 * *$ \\
\hline & Normal ( $\geq 30)$ & $28(25.9)$ & $12(10.4)$ & \\
\hline
\end{tabular}

Table 6. Evaluation of CARS Levels by Descriptive Characteristics

\begin{tabular}{|c|c|c|c|}
\hline \multirow{2}{*}{\multicolumn{2}{|c|}{ Autistic group $(n=108)$}} & \multicolumn{2}{|c|}{ CARS } \\
\hline & & Mild $(n=72)$ & Severe $(n=36)$ \\
\hline \multirow[t]{2}{*}{ Age (years) } & Min-Max (Median) & $3-13(6.5)$ & $2-15(7)$ \\
\hline & Mean $\pm S d$ & $6.78 \pm 2.53$ & $7.11 \pm 3.19$ \\
\hline \multirow[t]{2}{*}{ Gender; $n(\%)$} & Male & $62(66.0)$ & $32(34.0)$ \\
\hline & Female & $10(71.4)$ & $4(28.6)$ \\
\hline \multirow[t]{2}{*}{ Weight Z score } & Min-Max (Median) & $-2.3-3.5(0.6)$ & $-2.4-3.3(0.4)$ \\
\hline & Mean $\pm S d$ & $0.66 \pm 1.25$ & $0.44 \pm 1.32$ \\
\hline \multirow[t]{2}{*}{ Height Z score } & Min-Max (Median) & $-3-3.2(0.9)$ & $-2.8-2.8(0.6)$ \\
\hline & $M e a n \pm S d$ & $0.78 \pm 1.19$ & $0.40 \pm 1.41$ \\
\hline${ }^{a}$ Student $t$ Test & ${ }^{d}$ Fisher's Exact Test & & \\
\hline
\end{tabular}

Figure 1. Gender Distribution 
Table 7. Evaluation of Vitamin and Mineral Measurements by CARS Levels

\begin{tabular}{|c|c|c|c|c|}
\hline \multirow[t]{2}{*}{ Autistic group $(n=108)$} & & \multicolumn{2}{|c|}{ CARS } & \multirow[t]{2}{*}{$p$} \\
\hline & & Mild (n=72) & Severe $(n=36)$ & \\
\hline \multirow[t]{2}{*}{ Hemoglobin } & Min-Max (Median) & $9.6-14.2(12.6)$ & $9.9-14.6(12.2)$ & ${ }^{a} 0.071$ \\
\hline & Mean $\pm S d$ & $12.52 \pm 0.80$ & $12.19 \pm 0.99$ & \\
\hline \multirow[t]{2}{*}{ Iron } & Min-Max (Median) & $18-175(68)$ & $10-157(60)$ & ${ }^{c} 0.231$ \\
\hline & Mean $\pm S d$ & $73.95 \pm 34.98$ & $65.06 \pm 35.29$ & \\
\hline \multirow[t]{2}{*}{ Iron levels } & Low $(<50)$ & $18(25.0)$ & $10(27.8)$ & ${ }^{b} 0.756$ \\
\hline & Normal $(\geq 50)$ & $54(75.0)$ & $26(72.2)$ & \\
\hline \multirow[t]{2}{*}{ Vitamin B12 } & Min-Max (Median) & $107-1500(316)$ & $116-1500(368)$ & ${ }^{c} 0.577$ \\
\hline & Mean $\pm S d$ & $401.80 \pm 307.37$ & $412.63 \pm 304.73$ & \\
\hline \multirow[t]{2}{*}{ Vitamin B12 levels } & Low $(<200)$ & $13(18.1)$ & $6(16.7)$ & ${ }^{b} 0.858$ \\
\hline & Normal $(\geq 200)$ & $59(81.9)$ & $30(83.3)$ & \\
\hline \multirow[t]{2}{*}{ Folate } & Min-Max (Median) & $3.7-24(10.9)$ & $3.4-22(10.5)$ & ${ }^{c} 0.759$ \\
\hline & Mean $\pm S d$ & $11.20 \pm 4.57$ & $10.86 \pm 4.81$ & \\
\hline \multirow[t]{2}{*}{ Folate levels } & Low $(<5)$ & $3(4.2)$ & $4(11.1)$ & ${ }^{d} 0.219$ \\
\hline & $\operatorname{Normal}(\geq 5)$ & $69(95.8)$ & $32(88.9)$ & \\
\hline \multirow[t]{2}{*}{ Vitamin D } & Min-Max (Median) & $6.5-218(22.5)$ & $8-108(24.1)$ & ${ }^{c} 0.219$ \\
\hline & Mean $\pm S d$ & $27.33 \pm 26.65$ & $28.38 \pm 17.16$ & \\
\hline \multirow[t]{2}{*}{ Vitamin D levels } & Low $(<30)$ & $54(75.0)$ & $26(72.2)$ & ${ }^{b} 0.756$ \\
\hline & Normal $(\geq 30)$ & $18(25.0)$ & $10(27.8)$ & \\
\hline
\end{tabular}

Table 8. Correlation of CARS Scores and Vitamin and Mineral Measurements

\begin{tabular}{llc}
\hline Autistic group $(\boldsymbol{n = 1 0 8 )}$ & & CARS score \\
Hemoglobin & $\mathrm{r}$ & -0.182 \\
& $p$ & 0.061 \\
Iron & $\mathrm{r}$ & -0.087 \\
& $p$ & 0.372 \\
Vitamin B12 & $\mathrm{r}$ & 0.073 \\
& $p$ & 0.454 \\
Folate & $\mathrm{r}$ & 0.026 \\
& $p$ & 0.788 \\
Vitamin D & $\mathrm{r}$ & 0.073 \\
& $p$ & 0.452 \\
\hline
\end{tabular}

r: Spearman's Correlation Coefficient 


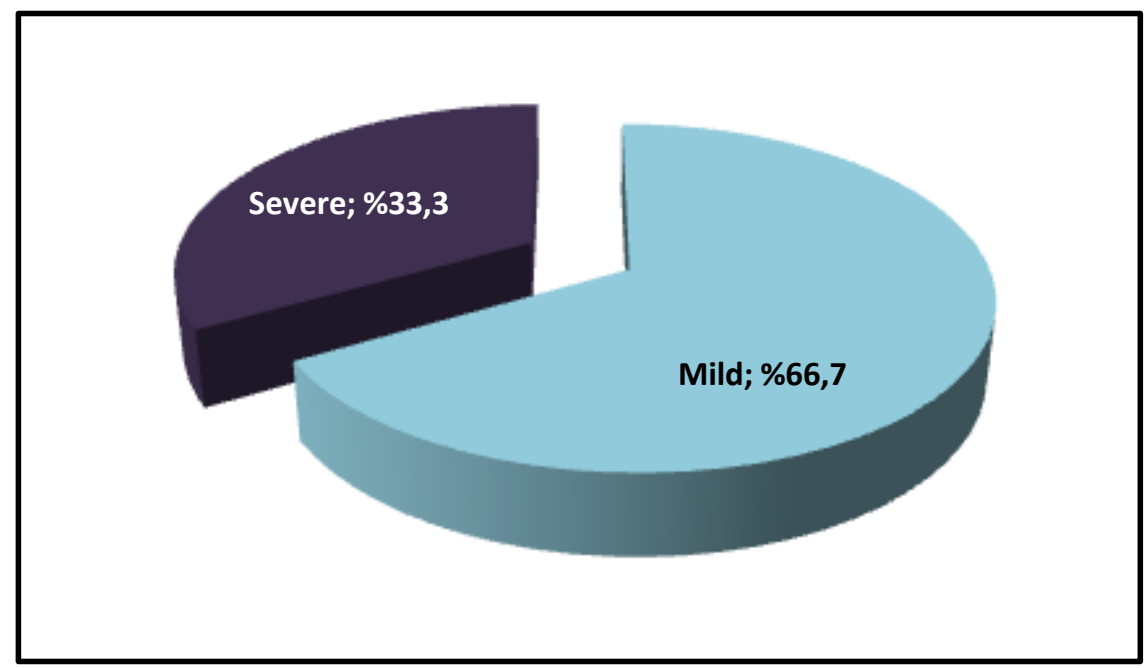

Figure 2. Severity According to the CARS Scores of Autistic Cases

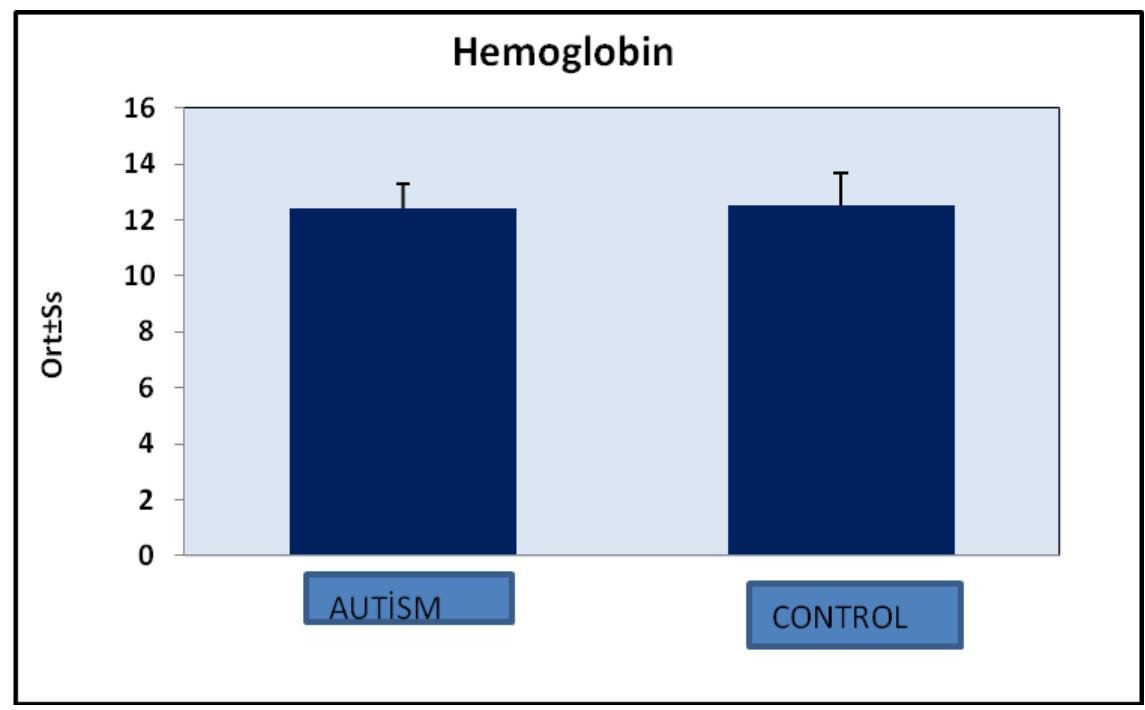

Figure 3. Distribution of Hemoglobin Measurements by Groups 


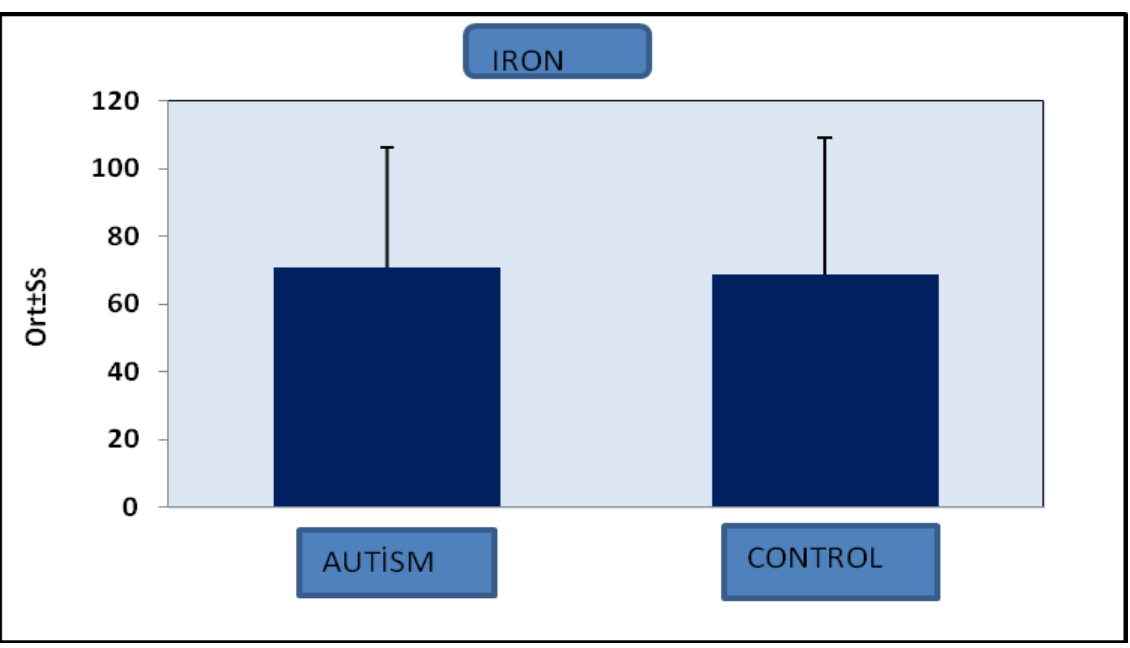

Figure 4. Distribution of Iron Measurements by Groups

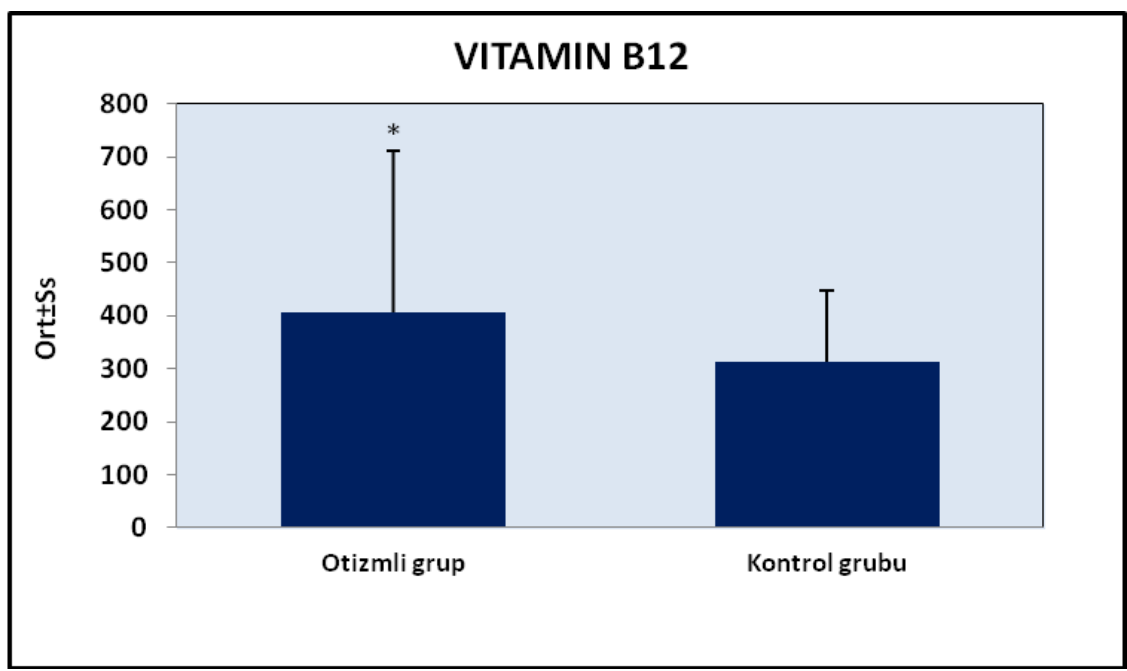

Figure 5. Distribution of Vitamin B12 Measurements by G.- ${ }^{*} p<0.05$

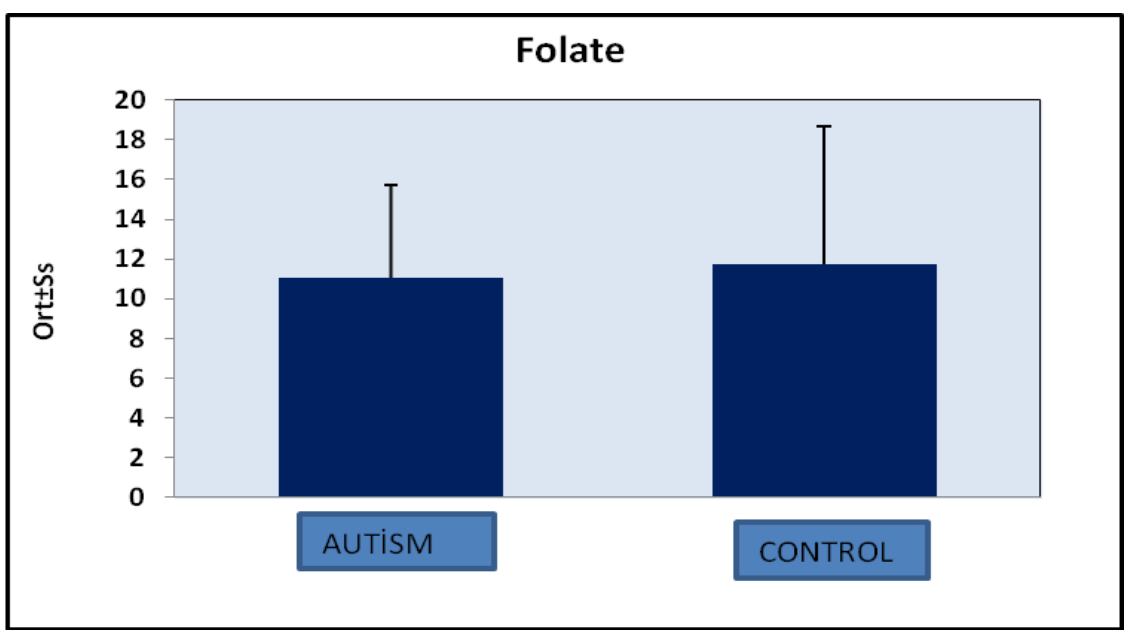

Figure 6. Distribution of Folate Measurements by Groups 


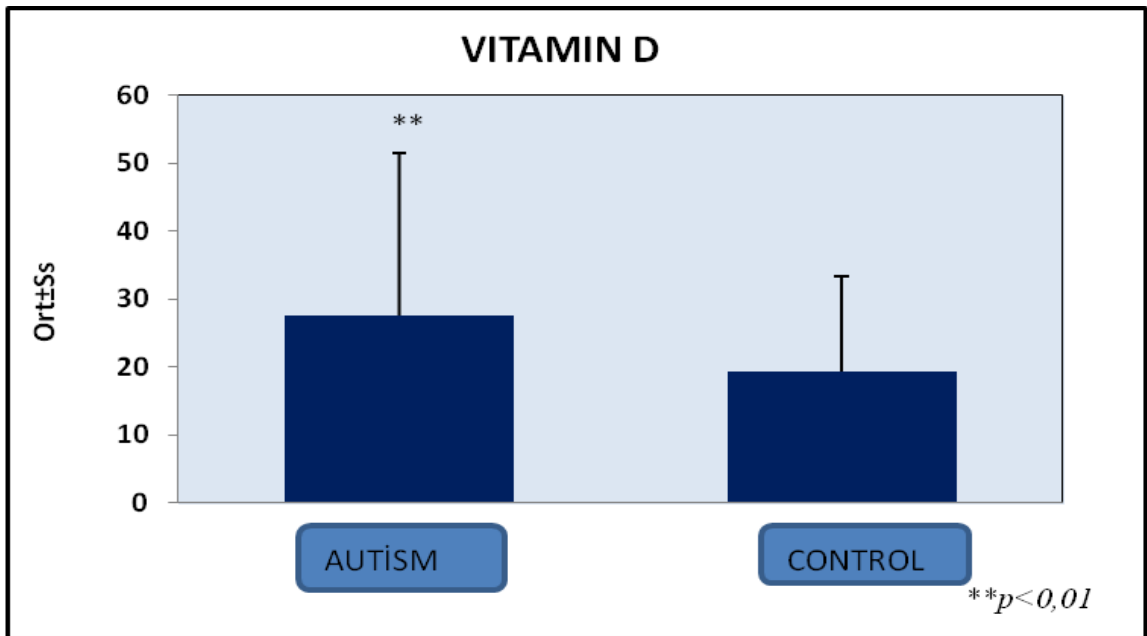

Figure 7. Distribution of Vitamin D Measurements by Groups

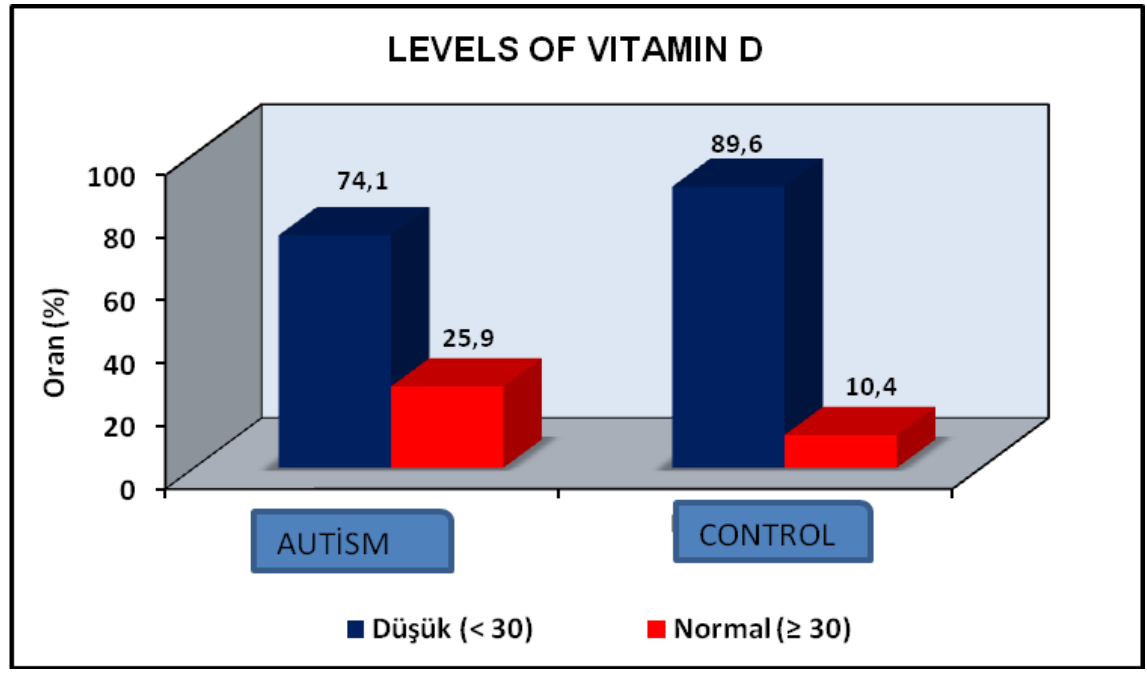

Figure 8. Distribution of Vitamin D Levels by Groups 